\title{
Artefactual episodic hypoxaemia during postoperative respiratory monitoring
}

Brian M.F. Lewer MB BCH FANZCA FFA (SA), DA (SA), Peter D. Larsen BSc, John $\mathrm{M}$. Torrance BSc MB BCH DA (UK), Duncan C. Galletly MB CHB FCANAES FANZCA

Purpose: To determine the reliability of continuous pulse oximetry in the detection of episodic hypoxaemia in total hip joint replacement patients. Episodic hypoxaemia has been described in postoperative patients and is associated with anaigesic technique. This study compared the incidence of hypoxaemic episodes identified solely by pulse oximetry and then subsequently where additional monitoring, as indicated for sleep-related breathing disorders, was also utilised.

Methods: Eight patients were studied on the night before and for three nights after surgery. Pulse oximetry, ECG, chest impedance, nasal and oral aiflow and transcutaneous $\mathrm{CO}_{2}$ were recorded. Sucden episodic hypoxaemia was defined as a decrease in oxygen saturation of $\geq 5 \%$ within two minutes, for $>$ five seconds and with a nadir of $<90 \%$. Artefacts were identified by noise signals on the ECG and impedance recordings and by a motion annotation wave superimposed on the oximetry trace.

Results: Using these criteria $172(79 \%)$ of 219 desaturation events were classified as artefactual. The median duration of genuine events was greater $(P<0.001$ Mann Whitney $U$ test) than artefactual events; 21 sec (range, 6 443) is I I sec (5-63). Genuine desaturations reached a median nadir of $\mathrm{SpO}_{2} 87 \%$ (range $83-89 \%$ ) compared with $81 \%$ $(61-88 \%)$ for the artefactual These differences were statistically significant $(P<0.001)$.

Conclusion: Previous studies utilising unobsenved pulse oximetry data alone may have overestimated the incidence of episodic hypoxaemic events in postoperative patients.

Objectif : Déterminer la fiabilité du saturomètre dans la détection des hypoxémies épisodiques chez des patients opérés pour mise en place de prothèses totales de hanche. Des hypoxémies épisodiques ont été décrites durant la période post-opératoire et sont associées à la technique analgésique. Cette étude compare l'incidence des épisodes hypoxérniques identifiés d'abord seulement par la saturométrie puis ensuite par l'utilisation de monitorage additionnel, indiqué pour des anomalies respiratoires reliées au sommeil.

Méthodes : Huit patients ont été étudiés la nuit précédant ainsi que les 3 nuits suivant la chirurgie. On enregistrait la saturométrie, l'ECG, l'impédance thoracique, le flot nasal et oral et la $\mathrm{PCO}_{2}$ transcutanée. L'hypoxémie épisodique subite était définie comme une chute de la saturation de $25 \%$ sur deux minutes, d'une durée de $>5$ secondes et avec un nadir à $<90 \%$. Les artéfacts étaient identifiés par des signaux représentant du bruit sur les enregistrements d'ECG ou d'impédance et par une onde due au mouvement surimposée sur l'onde du saturomètre.

Résultats : En utilisant ces critères, 172 (79\%) des 219 épisodes de désaturation ont été classifiés comme étant des artéfacts. La durée médiane des vrais épisodes de désaturation était plus grande $(P<0,001$ au test en $U$ de Mann Whitney) que celle des artéfacts, $21 \sec (e ́ c a r t ~ 6-443)$ vs II sec (5-63). Les vrais désaturations atteignaient un nadir de $87 \%$ (écart $83-89 \%$ ) alors que les artéfacts atteignaient $81 \%(61-88)$. Ces différences étaient statistiquement significatives $(P<0,001)$.

Conclusion : Les études précédentes utilisant des données provenant seulement de saturomètres sans points de comparaison peuvent avoir surestimé l'incidence d'hypoxémies épisodiques chez les patients en période postopératoire.

From the Section of Anaesthesia, Wellingron School of Medicine, P.O. Box 7343, Wellington, New Zealand.

Supported by a Research Grant from the Australian and New Zealand College of Anaesthetists.

Address correspondence to: Dr. Brian Lewer.

Accepted for publication Nopember 9, 1997. 
I N 1985 Catley $e t$ al. described the occurrence of episodic hypoxaemic events in sleeping postoperative patients who had received opioids. These events were detected by a combination of respiratory inductive plethysmography and ear oximetry. ${ }^{1}$

Subsequent studies ${ }^{2-5}$ reported a high incidence of such events following major orthopaedic, abdominal and vascular surgery when using pulse oximetry as the indicator of episodic hypoxaemia. It has been suggested that these hypoxaemic episodes may be a contributing factor in myocardial ischacmia ${ }^{5,6}$ and infarction, ${ }^{7}$ wound infection ${ }^{8}$ and mental confusion ${ }^{9}$ after surgery.

However, when comparing the methodology of these studies ${ }^{2-5}$ with standards published for cardiopulmonary sleep studies, discrepancies are apparent. ${ }^{10}$ Recommendations from the American Thoracic Society Consensus Conference on Indications and Standards for Cardiopulmonary Sleep Studies stipulate the assessment of sleep stages, respiratory airflow and effort, arterial oxygen saturation, body position, and periodic leg movements in the study of sleep related breathing disorders.

In this study, we examined the degree to which the incidence of episodic hypoxaemia, identified by unobserved pulse oximetry, could be attributed to artefactual recording error

\section{Method}

After obtaining Wellington Ethics Committee approval and informed consent we studied eight patients, mean age 66 (range, 53-77) yr, weight 75 (51-89) kg, undergoing primary unilateral total hip joint replacement surgery. Patients with a history of excessive daytime sleepiness or any neurological, cardiovascular or respiratory disease, which would classify them as ASA $>3$ were excluded.

Patients received oxygen $\left(4 \cdot \mathrm{min}^{-1}\right)$ via a Hudson mask and either intravenous PCA morphine or continuous lumbar epidural infusion (fentanyl and bupivacaine mixture) for the first two postoperative nights. These therapies were chosen as they are routinely used for this parient group in our hospiral.

Respiratory airflow was measured using a nasal and oral thermistor (Edentec Nellcor 971), respiratory effort using impedance pneumography (Edentec), pulse oximetry $\left(\mathrm{SpO}_{2}\right)$ with ECG linkage and motion annotation for artefact rejection (Edentec), and transcutaneous carbon dioxide ( $\mathrm{PtcCO}_{2}$ - Fastrac, Critikon) on the night prior to surgery and for three nights postoperatively from $10 \mathrm{pm}$ to $6 \mathrm{am}$. A Nellcor model D-YS pulse oximeter probe was applied to either forefinger using an adhesive wrap and then securely taped along the length of the upper limb. Neither the finger nor any portion of the upper limb was immobilised. Data were recorded on a $486 \mathrm{PC}$.

An episodic event was defined as a decrease in oxygen saturation of $25 \%$ within a two minute period, which lasted for five seconds and had a nadir of < $90 \%$. Each event was identified and then examined by two independent observers. When both a) noise in the ECG and Chest Impedance tracings at the onset of the desaturation and b) a motion annotation wave superimposed on the pulse oximetry tracing were present, an event was classified as artefactual. If these began after the onset of desaturation, they could have followed an arousal response secondary to the desaturation, and therefore the event was classified as genuine.

\section{Results}

A total of 219 hypoxaemic events over the 32 nights of monitoring were recorded using pulse oximetry criteria alone (Table). Forty seven (21\%) of these events were judged as genuine and $172(79 \%)$.as artefacts. An example of each is shown in Figure 1.

TABLE Pulse oximetry saturation events.

\begin{tabular}{lcccc}
\hline & & \multicolumn{3}{c}{ Postoperative nights } \\
$\begin{array}{l}\text { Hypoxatmic } \\
\text { episodes }\end{array}$ & $\begin{array}{c}\text { Preoperative } \\
\text { night }\end{array}$ & Night one & Night two & Night three \\
\hline Total per night & 43 & 22 & 94 & 60 \\
Artefactual & 37 & 20 & 63 & 52 \\
Genuine & 6 & 2 & 31 & 8 \\
\hline
\end{tabular}

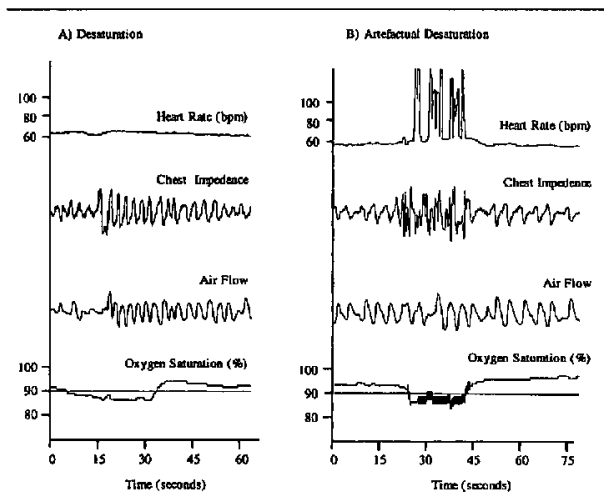

FIGURE 1 An event was classified as artefactual if a) noise appeared in the ECG and Chest Impedance tracings at, or prior to, the onset of the desaturation and b) a motion annotation wave was superimposed on the pulse oximetry tracing. This is shown in B) as a high frequency, fixed amplitude wave superimposed onto the pulse oximetry trace. 
The median duration of genuine events was greater $(P<0.001$ Mann Whitney $U$ test $)$ than artefactual events; $21 \mathrm{sec}(6-443 \mathrm{sec})$ vs $11 \mathrm{sec}(5-63 \mathrm{scc})$.

Genuine desaturations reached a median nadir of $\mathrm{SpO}_{2} 87 \%$ (range $83-89 \%$ ) compared with $81 \%$ (range $61-88 \%)$ for the artefactual $(P<0.001$ Mann Whitney U test).

Two independent observers performed the analysis. The interrater observation agreement was high with only three of the artefactual events not identified by both observers. These three events were included as genuine after review by both observers.

\section{Discussion}

Catley and co-workers described episodic ventilatory dysfunction in sleeping postoperative patients receiving $i v$ morphine. Impedance plethysmography and ear oximetry (model HP 47201A), which is a transmittance rather than a pulse oximeter and is unaffected by sensor movement, were used to detect episodes of ventilatory disturbance associated with desaturation. ${ }^{1}$ Subsequent studies by others have used pulse oximetry as a sole identifier of desaturation episodes. ${ }^{2-5}$

In our study, hypoxaemic episodes were examined using a) direct visual inspection of the ECG, impedance and oximetry traces and $b$ ) the motion detection system of the Edentec monitor. The latter records $\mathrm{R}-\mathrm{R}$ intervals from the ECG and compares these times with pulse wave intervals from the pulse oximeter. A motion artefact annotation is added to the oximeter trace when pulsations are not synchronous with the ECG (Figure 1), indicating there is signal interference. Approximately $80 \%$ of desaturations detected by pulse oximeter occurred in the presence of concomitant episodic electrical interference and motion annotation. This is consistent with a recent study using the Nellcor N200 pulse oximeter in the recovery room setting where $87 \%$ of "events" were identified as motion artefacts. ${ }^{11}$ Motion related artefacts are accentuated by siting the sensor on a finger, as was done in our study and has been done in previous studies reporting high incidences of postoperative hypoxaemia. ${ }^{2-5}$

The overall incidence of desaturation (artefactual plus genuine) events that we observed was comparable with that documented by Rosenberg et al. using pulse oximetry alone in hip replacement patients. ${ }^{3}$ However, they did not attempt to confirm the events as being true desaturations by either direct patient observation or by monitoring other respiratory parameters as recommended in the American Thoracic Society Consensus guidelines. ${ }^{10}$

We recorded the highest incidence of hypoxaemic events during the second postoperative night as have previous investigators. ${ }^{3}$ Postulated causes of this phe- nomenon include altered sleep patterns with rebound of REM sleep, abnormalities of control of breathing and non-compliance with oxygen therapy. ${ }^{2-5}$ In addition, genuine events were more likely to be of a longer duration and a higher oxygen saturation level than artefactual events. Our findings may explain why attempts to link hypoxaemic episodes to adverse outcomes have not been conclusive.

We conclude that studies of episodic desaturation, based purely on finger pulse oximetry may considerably overestimate the incidence of hypoxaemia.

\section{Acknowledgment}

The authors are indebted to Paterson Distributors, New Zealand, for the technical assistance provided.

\section{References}

1 Catley DM, Thornton C, Jordan C, Lehane JR, Royston $D, J o n e s J G$. Pronounced, episodic oxygen desaturation in the postoperative period: its association with ventilatory pattern and analgesic regimen. Anesthesiology $1985 ; 63: 20-8$.

2 Rosenberg J, Wildscbiadtz G, Pedersen $M H$, pon Jessen $F$, Kehlet $H$. Late postoperative nocturnal episodic hypoxaemia and associated slecp pattern. Br J Anaesth 1994; 72: 145-50.

3 Rosenberg J, Pederson MH, Gebubr $P$, Keblet $H$. Effect of oxygen therapy on late postoperative episodic and constant hypoxaemia. Br J Anaesth 1992; 68: 18-22.

4 Reeder $M K$, Goldman $M D$, Lab $L$, et al. Fostoperative hypoxaemia after major abdominal vascular surgery. Br J Anaesth 1992; 68: 23-6.

5 Rosenberg J, Rasmussen V, von Jessen $F$, Ullstad $T$, Kehlet $H$. Late postoperative episodic and constant hypoxaemia and associated ECG abnormalities. Br J Anaesth 1990; 65: 684-91.

6 Reder $M K$, Muir $A D$, Fö̈x $P$, Goldman $M D$, Loh $L$, Smart D. Postoperative myocardial ischaemia: temporal association with nocturnal hypoxaemia. Br J Anaesth 1991; 67: 626-31.

7 Pateman JA, Hanning CD. Postoperative myocardial infarction and episodic hypoxaemia (Editorial). Br J Anaesth 1989; 63: 648-59.

8 Knighton $D R$, Fiegel VD, Haiverson $T$, Schneider $S$, Brown $T$, Wells CL. Oxygen as an antibiotic. The effect of inspired oxygen on bacterial clearance. Arch Surg $1990 ; 125$ : 97-100.

9 Rosenberg J, Keblet H. Postoperative mental confusion-association with postoperative hypoxaemia. Surgery 1993; 114: 76-81.

10 American Thoracic Society. Indications and standards for cardiopulmonary sleep studies. Am Rev Respir Dis 1989; 139: 559-68. 
11 Dumas C, Wabr JA, Tremper KK. Clinical evaluation of a prototype motion artifact resistant pulse oximeter in the recovery room. Anesth Analg 1996; 83: 269-72.

12 Langton JA, Hanning $C D$. Effect of motion artefact on pulse oximeters: evaluation of four instruments and finger probes. $\mathrm{Br} \mathrm{J}$ Anaesth $1990 ; 65: 564-70$. 